\title{
Cloud Computing Technology: Reducing carbon footprint in beef supply chain
}

\begin{abstract}
Global warming is an alarming issue for the whole humanity. The manufacturing and food supply chains are significantly contributing to the large-scale carbon emissions. Beef supply chain is one of the segments of food industry having considerable carbon footprint throughout its supply chain. The major emissions are occurring at beef farms in the form of methane and nitrous oxide gases. The other carbon hotspots in beef supply chain are abattoir, processor, logistics and retailer. There is huge amount of pressure from government authorities to all the business firms to cut down carbon emissions. The different stakeholders of beef supply chain especially small and medium sized stakeholders, lack in technical and financial resources to optimize and measure carbon emissions at their end. There is no integrated system, which could address this issue for the entire beef supply chain. Keeping the same in mind, in this paper, an integrated system is proposed using Cloud Computing Technology (CCT) where all stakeholders of beef supply chain can minimize and measure carbon emission at their end within reasonable expenses and infrastructure. The integrated approach of mapping the entire beef supply chain by a single cloud will also improve the coordination among its stakeholders. The system boundary of this study will be from beef farms to retailer involving logistics, abattoir and processor in between. The efficacy of proposed system is demonstrated in a simulated case study.
\end{abstract}

Keywords- Carbon Footprint, Beef Supply Chain, Cloud Computing Technology (CCT)

\section{Introduction}

Carbon emission in the environment is becoming a crucial issue and having wide range of consequences for both society and climate. Climate change and global warming are drawing attention of all stakeholders of supply chain from various industries (Shaw et al. 2013). The UK government has decided to curtail carbon emission by $80 \%$ till 2050 (Barker et al, 2014). All major industries and organizations are looking for ways to cut down carbon emissions in their supply chain and have fewer burdens on environment. There is a considerable uncertainty in terms of methods followed for measuring the carbon footprint in both future and existing businesses. Most of the businesses are currently working on minimizing carbon footprint at segment level in a supply chain. Carbon emission occurring at one segment of supply chain is affecting the emission at other segments as well. There is no emphasis given on an integrated approach of reducing carbon footprint of whole supply chain.

The term carbon footprint is getting wide range of attention from academic personnel and practitioners. The widely used definition of carbon footprint is "A carbon footprint measures the total greenhouse gas emissions caused directly and indirectly by a person, organization, event or product" (Carbon Trust, 2012).

*1Corresponding Author. Tel: +44 (0) 1970622529

E-mail: aks10@aber.ac.uk (Akshit Singh) 
Beef is vital source of protein and is widely consumed across the globe. It accounts for almost $24 \%$ of global meat production (Boucher et al, 2012). According to Environmental Protection Agency, livestock is responsible for approximately $3.4 \%$ of the global greenhouse gas emissions. The whole supply chain of beef is associated with carbon emission. However, major carbon emission is occurring at beef farms alone (EBLEX, 2012). The main reason behind it is the emission of methane from the cattle because of the process called enteric fermentation. The methane is a greenhouse gas, which is 25 times more potent than carbon (Forster et al. 2007). Abattoir, processor, retailer and logistics are also emitting significant amount of carbon at their end. The primary reason behind this is the energy used in their premises like electricity, diesel etc. and the fuel used for logistics.

Conventionally, carbon footprint measurement in the beef industry is also done in a segregated way i.e. at farm, abattoir, retailer and logistics level. The availability of integrated model for measuring carbon footprint in beef industry as a whole is very rare. However, in this study, it is proposed using the principles of Life Cycle Assessment (LCA). This approach considers the carbon emission in the product flow of beef from cradle to grave. LCA model for beef supply chain is depicted in Figure1. The system boundary of this study is from farm to retailer.

$<<$ Include figure $1>>$

In the past, Cloud Computing Technology (CCT) is used to integrate the segregated segments of a particular industry using minimum resources. It has given excellent results and has wide range of applications in various industries like banking, manufacturing, IT etc. It makes the information visible to all segments of an industry by deploying its service delivery models like Software as a Service (SaaS), Platform as a Service (PaaS) and Infrastructure as s Service (IaaS). Keeping these attributes in mind, CCT is deployed here to minimize carbon footprint of entire beef supply chain. The retailer, being a key stakeholder is going to maintain a private cloud, which will map the entire beef supply chain. The information related to carbon footprint associated with every stakeholder will be available on the cloud. This information will be accessible to all of them by using basic computing and Internet equipment.

The organization of the article is as following: Section 2 includes the literature review. Section 3 consists of explanation of Cloud Computing Technology (CCT). Section 4 comprises of explanation of Beef supply chain and utilization of cloud in measuring its associated carbon footprint. A case study on application of cloud computing in measurement of carbon footprint of entire beef supply chain is incorporated in Section 5. Section 6 embodies managerial implications, which is followed by conclusion in Section 7.

\section{Literature Review}

Peters et al. (2010) have assessed the carbon footprint of red meat supply chains in Australia and compared them with that of international studies on red meat production. They considered three supply chains (sheep, beef and premium export beef) in different parts of Australia and used Life Cycle Assessment (LCA) technique to measure their carbon footprint. Consequently, it was found out that carbon footprint of Australian red meat supply chains are either average or below average when compared to International studies on red meat supply chain. They also 
emphasized that feedlot based cattle have lower carbon emissions than grassland based cattle. Desjardins et al. (2012) have reported the carbon footprint for beef in Canada, European Union, USA, Brazil and Australia. The decline of carbon emission associated with beef industries was reported in the last thirty years in abovementioned countries along with the reasons. It was also suggested to allocate carbon emission to the by-products obtained from beef like hide, offal, fat and bones. Therefore, they have expressed carbon emission for beef as $\mathrm{CO}_{2}$ eq. / $\mathrm{kg}$ of beef. Kythreotou, et al (2011) proposed a method to calculate the greenhouse gas emissions caused due to energy usage (electricity, LPG, diesel etc.) in breeding of cattle, pig and poultry in Cyprus. The greenhouse gas emission of each energy source and the corresponding consumption by livestock species mentioned were calculated to obtain the aggregate results. This study has excluded the greenhouse gas emission due to transport and the impact of anaerobic digestion. The results obtained were compared to the major emissions in breeding of livestock, which are manure management and enteric fermentation. Bustamante et al, (2012) have determined the Greenhouse Gas (GHG) emission from the cattle farming from year 2003 to 2008. The root causes for the GHG emissions were identified. Their study showed that GHG emissions associated with cattle raising accounts for almost half of aggregate GHG emissions done by Brazil. Some policies for public and private sector were proposed to mitigate the GHG emissions associated with cattle farming. Schroeder et al (2012) calculated the carbon footprint of three beef supply chains, two from UK and one from Brazil. They have used Life Cycle Assessment (LCA) methodology for their calculations and taken the phenomenon of carbon sequestration into account. It was found out that maximum emission is at farm end as compared to slaughterhouse, logistics, etc. Some suggestive measures were given like increasing the weaning rate and reducing age of slaughter from 30 to 24 months for reduction of carbon footprint associated with beef supply chain. Bellarby et al (2013) have investigated the GHG emission associated with the livestock supply chain (from production to consumption and wastage) in EU27 in year 2007. Their analysis showed that main reasons of emissions were livestock farms, Land Use and Land Use Change (LULUC) and food waste. The reduction in waste, consumption and consequent production to reduce GHG emiss ions were emphasized. They have also given some recommendations for mitigation of GHG emission like use of grassland based farms instead of intensive grain production for raising cattle. Ogino et al (2007) have assessed the environmental consequences of beef cow calf system in Japan. The system boundary of this study was the processes involved in cow calf system like feed production and transportation, animal welfare etc. and the method used for analysis were LCA. Their study showed the impact of one calf in its whole lifetime on environment in terms of greenhouse gas emission, eutrophication, acidification and energy consumption. It was also found out that reducing the calving interval by one month and increasing the weaning rate can reduce the impact of cow calf system on environment in all above-mentioned categories. The next section consists of description of Cloud Computing Technology (CCT).

\section{Cloud Computing Technology (CCT)}

Cloud computing is an easy to adopt technology with simple and latest architecture (Hutchison et al., 2009). This architecture presents information technology (IT) as a paid service in terms of deployment and maintenance (Sean et al, 2011). Cloud computing technology is not a new concept for most of the sectors like banks, automobile, retail, health care, education, logistics (Al-Hudhaif et al., 2011). Various 
deployments models of cloud computing makes the adoption easy for any type of sector, depending on the need of usage. This innovative technology makes the collaboration easier among companies by use of cloud (XunXu, 2012). Some of the main benefits of cloud computing are hardware and software cost reduction, better information visibility, computing resources being managed through software as a service and faster deployment.

CCT have three service delivery models, which are Software as a Service (SaaS), Platform as a Service (PaaS) and Infrastructure as a Service (IaaS). These services are delivered through industry standards such as service-oriented architecture (SOA). $\mathrm{SaaS}$ is an application that is hosted as a service and provided to customers by using Internet. Service providers look after the software maintenance and support associated with the application. For example, CRM, Google Office, Salesforce, Netsuite etc. PaaS provides a computing platform i.e. networks, servers, storage and other services. Consumer creates the software and also controls software deployment and configuration settings. Examples are Facebook F8, Salesforge App Exchange, Google App Engine, Joyent, Azure etc. IaaS provides storage, network capacity, and other computing resources on rent basis. Customer uses the infrastructure to deploy their service and software. They can manage or control the OS, storage, apps and network components. Examples of IaaS are OpSource, Blizzard, terremark, Gogrid etc.

There are three types of cloud deployment models i.e. public, private and hybrid cloud, which are shown in Figure 2. Public cloud is a cloud that is provided by third party service provider e.g. Google, Amazon via the Internet. It is easy and cost effective way to deploy IT solution by the pay as you go concept. Google Apps is an example of a public cloud that is used by many organizations of all sizes (Sean et al, 2011). A private cloud offers many of the benefits of a public cloud-computing environment. It provides greater control over the cloud infrastructure, and is often suitable for larger installations. It is also manageable by third-party provider (Sean et al, 2011). A hybrid cloud is a combination of a public and private cloud i.e. noncritical information is outsourced to the public cloud, while business, confidential, mission critical services and data are kept within the control of the organization (Sean et al, 2011).

$<<$ Include figure $2>>$

The above-mentioned model in Figure 2 makes cloud computing an ideal choice for any industry irrespective of its scale. Big companies who already have their big IT infrastructure and cannot go immediately towards expansion because of agile environment of business, they can buy services from third party companies like Google and Amazon and go over cloud to meet the ever changing demand of technology. Companies having offices or branches across the globe can use cloud as a means of connectivity and put their generalized applications over the cloud through SaaS (software as a service). CCT appears to small and medium size firms as an easy startup. For small firms, who are going to start their business straight away and do not have resources to invest on IT infrastructure can make use of services provided by third party service providers like Google and Amazon. They adopt the approach of pay as you go and get benefits of IT services with their existence over the cloud. 
These firms also use SaaS to create their profile over the cloud and make themselves available to the global competitive environment of business.

The use of CCT is very less in food sector especially in measurement of carbon footprint. In this article, cloud-computing architecture, as shown in Figure 3, has been designed to minimize the carbon footprint of entire beef supply chain. In the proposed architecture, all stakeholders of beef supply chain viz. farm, processor and retailer are mapped. All stakeholders of beef supply chain can utilize the benefit of different software available on cloud using SaaS concept.

$<<$ Include figure $3>>$

\section{Cloud Based Beef Supply Chain and Associated Carbon Footprint}

This section briefly describes the different stakeholders of beef supply chain and the corresponding sources of carbon emission. The schematic diagram of beef supply chain is shown in Figure 4. In the beef farms, farmers raise the cattle till the age of 3 months to 30 months depending upon the breed and demand of cattle in the market. When cattle reach their finishing age, they are transferred to abattoir and processor using logistics. Cattle are slaughtered in the abattoir and cut into primals. These primals are then processed into products like steak, mince, joint, dicer/stir-fry, burger/meatball etc. These products are then packed and labeled. The packed beef products are then sent to retailer using logistics.

\section{$<<$ Include figure $4>>$}

There are various sources of carbon emission in the entire beef supply chain. These are known as carbon hotspots, which are discussed for all the stakeholders as following: -

4.1 Farm - The beef farms are responsible for the maximum amount of carbon emission occurring in the whole beef supply chain (EBLEX, 2012). The major factors responsible for this emission (carbon hotspots) are described as following: -

1. Enteric Fermentation -It is a process occurring in the digestive system of cattle where they convert the feed into methane gas and release in to the environment. Methane gas is very hazardous Greenhouse Gas (GHG). It is 25 times more potent than carbon dioxide for causing global warming. The process of enteric fermentation is the major reason of carbon footprint in the beef supply chain. It is dependent on the breed of cattle. For example, bull beef releases less methane than dairy cows. Moreover, the number of cattle in a farm also affects the impact of this phenomenon.

2. Manure-The manure of cattle releases various GHGs like methane, nitrous oxide, ammonia and other oxides of Nitrogen. Therefore, efficient manure handling plays a significant role in reducing the carbon footprint at farm end.

3. Fertilizer used for feed - The fertilizer applied to the grasslands or to the crops grown for feed of cattle release various GHGs, predominantly Nitrous oxide. 
The potency of Nitrous oxide is 298 times more than carbon dioxide (Forster, et al, 2007). Therefore, the rate of application of fertilizer (in $\mathrm{kg} / \mathrm{ha}$ of grassland) should be optimum as it has a significant carbon footprint associated with it. Beef farmers especially, who are growing feed for the cattle on their own might not be aware of it. They must be informed about the hazards associated with excess application of fertilizer as it can also penetrate into the meat derived from cattle as well.

4. Energy used - The energy (electricity, diesel etc.) used at beef farms and at the farms where feed for cattle are grown is also responsible for carbon footprint. However, their impact is much less as compared to methane and nitrous oxide generated from above mentioned sources. Moreover, there is a variation in the carbon footprint depending upon the source of energy used. For example, renewable energy has zero carbon footprint and electricity has lower carbon footprint than diesel or other fossil fuels.

The above-mentioned factors (carbon hotspots) highlight the potential sources of carbon emission at farm end in beef supply chain. The primary reasons for carbon emission are enteric fermentation and the fertilizers used for the feed. There are various carbon calculators available in the market for measuring carbon footprint at beef farms having their respective advantages \& disadvantages. These calculators are often very expensive. Usually, small beef farmers are lacking in financial and technical awareness. They get confused in selecting a particular calculator for their farms to obtain more precise results. In the proposed architecture, retailer will select an appropriate and user-friendly calculator for their farms and will upload it on the private cloud. The farmers can use these calculators to minimize the carbon footprint using Software as a Service (SaaS) concept. They will feed relevant information about their farms in the carbon calculator and obtain current emission results and suggestions for reducing carbon footprint. More information about the input and output to/from these calculators is presented in the case study (Section 5). This phenomenon is depicted in Figure 5. The calculator will further give the feedback to reduce their carbon footprint. It will help farmers to take appropriate decision and bring necessary changes in their practice. Finally, farmers will estimate carbon emission at their end and this information will be visible to all stakeholders of beef supply chain. It will further boost the coordination among the stakeholders in improving the product flow and reducing the carbon footprint.

\section{$<<$ Include figure $5>>$}

4.2 Logistics - The logistics of beef supply chain is very complex as compared to other industries. It has to take various factors into consideration. Such as the vehicles used for carrying beef products is temperature sensitive. There is a restriction in terms of maximum number of cattle, which can be carried in a vehicle and the maximum journey they can travel. They have to also take into account the stress factor in the cattle, which can degrade the meat quality and its associated shelf life. For example, they have to take certain precautions like keeping sexually active animals of opposite sex separately, keeping familiar animals together, keeping animals with horns separately from animal without horns etc. Usually, the logistics associated with small and medium beef farms are 
only concerned about these major factors. They were not able to address the carbon emission associated with logistics processes. However, the carbon calculator proposed in this study will equip them appropriately to cope with these issues. There are numerous sources of direct and indirect carbon emissions among which the major emission is because of the GHGs released from exhaust of the vehicles used for transportation of cattle or beef products. These sources of carbon emission in logistics are described as following: -

1. Distance - The carbon footprint generated from logistics is directly proportional to the distance travelled by them. However, farm enterprise has to keep in mind the government regulations associated with the maximum journey time of cattle. For example in UK, after a journey of 14 hours, they must be given a rest of 1 hour (DEFRA, UK). During the rest, they are provided with liquid and could be fed as well. Thereafter, they can go for another 14-hours journey. If they haven't reached the destination yet, then the cattle needs to be unloaded and given rest at a EU approved control post where they are appropriately fed and watered. Therefore, mechanism of CCT in this study will suggest the shortest and less busy route within the government regulations by the logistics firm to reduce their carbon footprint.

2. Number of Cattle- The number of cattle allowed in a vehicle should be as per the space allowance mentioned in the Government regulations (DEFRA, UK). These space allowances are based on the weight of the cattle. If they are not followed, cattle get stressed and have a huge impact on meat quality and its shelf life. The product, which will be lost due to these reasons, will be replaced by another similar product with the same amount of carbon footprint associated with it. Hence, it leads to additional burden on the environment.

3. Temperature sensitive vehicle- The temperature guidelines from government authorities should be taken into consideration by the logistics firms. For example, in UK, while transporting cattle, the temperature should not fall below zero degrees Celsius. Similarly, for transporting fresh beef products, the temperature of +3 degrees Celsius must be maintained in the carrier vehicle. Keeping these requirements in mind, appropriate decision must be made in selecting a vehicle, which meet these requirements and have minimum emission in its category. Moreover, these vehicles should be fitted with best quality catalytic converter so that they can reduce the intensity of the carbon emissions.

4. Load optimization- There might be inefficient load optimization procedures followed by the logistics firms. It should be addressed and ensure that minimum number of vehicles are used for the delivery of beef products thereby reducing the carbon footprint associated with them.

5. Means of transport- The selection of means of transport should be done wisely so as to reduce the carbon emission from it. For example, rail freight transport can be used if possible instead of lorries as it runs on electricity instead of fossil fuel and hence less carbon footprint associated with it. 
6. Use of alternative fuel- The emphasis must be made to adulterate the fuel used in the vehicles with biodiesel, ethanol or other alternative fuel to reduce the carbon footprint associated with them.

The aforementioned factors (carbon hotspots) describe the root causes of carbon emission at logistics end. The major concerns for logistic firms are increasing profit and expanding their business. There is considerable pressure from government authorities to reduce the carbon footprint. Sometimes, SMEs logistic firm do not have technical expertise and financial resources to select an appropriate calculator to measure the carbon footprint. Keeping these criterions in mind, retailer has selected an appropriate carbon calculator for their logistic firms and uploaded it on the private cloud. Logistic firm can use these calculators to measure carbon emission using Saa S concept. Calculator will also give them feedback to reduce their carbon footprint. This will help logistic managers to take optimal decision and can bring corresponding changes in their operation. The information entered by logistics in calculator and the results obtained will be visible to all the stakeholders of beef supply chain. This process will help to improve the coordination between logistics and other stakeholders. For example, it will suggest the beef farms when to stop feeding cattle so that they can be collected by logistics firms for transporting them to abattoir.

4.3 Abattoir \& Processor- The major emission from abattoir and processor is because of the utility used at their premises and fractionally from animal byproducts produced during processing of beef. The major factors responsible for carbon footprint at abattoir and processor are described as following: -

1. Energy - The abattoir and processor plant consumes huge amount of energy for their operations. Therefore, it is crucial to use cleaner energy sources like renewable source of energy. For example, wind energy, solar or electricity derived from hydroelectric power plants.

2. Animal byproducts - The animal byproducts apart from specified risk material (brain, spinal cord etc.), when disposed to landfill leads to emission of methane. They could be used in composting and generation of biogas. Hence, reducing the resultant carbon footprint associated with them.

3. Packaging- The manufacturing of fresh packaging of beef consumes huge amount of resources and energy and therefore a potential source of carbon emission. There should be emphasis made to blend the fresh packaging with recycled content. Moreover, bigger packaging material like pallets and big trays should be reused and $100 \%$ recycled.

4. Forecasting - The amount of beef products processed in the abattoir and processor might not be proportionate to the forecasted demand of the retailer. Therefore, modern techniques and personnel should be deployed for better forecasting. This process can reduce significant amount of beef products going waste thereby saving the carbon footprint involved in manufacturing of equivalent fresh products. 
5. Maturation of carcass- It is a process occurring after slaughtering the cattle. The carcass is kept in a freezing temperature of 1 degree Celsius from 7-21 days in Maturation Park depending upon age, gender and breed of cattle. There must be strong provision made so that the carcasses doesn't get over matured, as there is huge consumption of energy in maintaining the freezing temperature in Maturation Park. Hence, it is a potential source of carbon emission, which could be reduced by efficient management.

At abattoir and processor, the major carbon emission is from the energy utilized for their operations. The retailer has closely inspected their operations and selected a carbon calculator for them. The retailer is maintaining a private cloud for the entire beef supply chain and uploaded this calculator on it. They have further provided the access to private cloud and the appropriate training to use it to the abattoir and processor personnel. Now, the abattoir and processor personnel can access the carbon calculator using basic computing and Internet equipment in the form of SaaS. They will enter the required information in the calculator and obtain the results for their emission. Calculator will also give them feedback to reduce their carbon footprint. The policy makers at abattoir and processor will do the optimal decision-making and bring corresponding changes in their operation. Finally, they will deploy the calculator again and measure their carbon footprint. The information entered by them to the calculator and the results obtained will be visible to all the stakeholders.

4.4 Retailer - The major carbon footprint associated with retailer is because of the energy consumption and the beef products getting waste because of inefficient management. These factors are described as following: -

1. Energy usage- The retailer stores consumes huge amount of energy for their operations like refrigeration, air conditioning etc. Therefore, it is crucial to use cleaner energy sources like renewable source of energy like wind, solar or electricity derived from hydroelectric power plants.

2. Forecasting - The amount of beef products ordered by retailer might not be proportional to the forecasted demand of the customers. Moreover, some retailer order more products to make their shelf look full and often these products remains unsold and ran out of their shelf life. The transportation of waste products to anaerobic digestion plant or landfill again creates an unnecessary carbon footprint. Therefore, modern techniques and personnel should be deployed for better forecasting considering all the factors like weather, promotions etc. This process can reduce significant amount of beef products going waste thereby saving the carbon footprint involved in manufacturing of equivalent fresh products.

3. Lack of coordination- There might be lack of coordination between the retailer and abattoir and processor and in terms of quantity of beef products being ordered and sent respectively. Sometimes, more beef products are delivered to retailer than that being ordered. Then, the excess products are sent back to abattoir and processor via reverse logistics and an unnecessary carbon footprint is generated. Moreover, the shelf life of 
fresh beef products is very small and a crucial amount of that is wasted in this process.

4. Efficient \& skilled labour- The labour employed in the retailer store might not be perfectly trained so that beef products does go waste because of mishandling or not following the procedures of stacking and shelving.

The above-mentioned factors highlight the major factors (carbon hotspots) responsible for carbon emission at the retailer end. Carbon emission occurring at retailer end is the cumulative of individual emissions of all retailer stores operating. Retailer has taken the initiative to cut down the carbon emission of entire beef supply chain. Therefore, they are maintaining a private cloud for all the stakeholders of beef supply chain. They have selected a particular carbon calculator for retailer stores and uploaded it on the private cloud. These stores will access this calculator in the form of SaaS via basic computing and Internet equipment and enter the relevant information. The calculator will generate results for their carbon emission and it will further give the feedback to reduce their carbon footprint. The retailer stores will do the optimal decision-making and bring relevant changes in their operation. Finally, they will deploy the carbon calculator again and measure their carbon footprint. The information entered by a particular retailer store to the calculator and the results obtained will be visible to all other retailer stores and the stakeholders of the beef supply chain.

\section{Case Study: Application of CCT in Beef Supply Chain}

This section describes the execution of the framework described in Section 3. It involves a retailer of beef products operating various stores across the country. The cattle for these beef products are grown in different beef farms. An abattoir and processor firm, who has several branches nationwide, then processes these cattle. The processed beef products are then brought into stores of the retailer for selling to the consumers. Retailer wants to cut down the carbon emission of its entire supply chain because of government's pressure. The targeted goal cannot be achieved by optimizing the operation and management practices of retailer stores alone. Retailer took an initiative to involve other stakeholders of beef supply chain in this process. When the policymakers of retailer interacted with beef farmers about carbon footprint generated in their farms, they observed that farmers lack in technical and financial resources to address it. The carbon calculators available in market are complicated having their respective advantages and shortcoming. It was really hard for farmers to select and use an appropriate calculator for their business. The same issues were identified for remaining stakeholders viz. logistics and abattoir and processor as well. Logistics personnel reported that they are trying their best to reduce carbon footprint at their end by taking certain measures like taking shortest possible route etc. However, it was not sufficient enough to meet the target. During the discussion, it was revealed that a significant amount of avoidable carbon footprint is generated because of lack of coordination among stakeholders. As a result, retailer realized that there is need of a mechanism, which could help all stakeholders to minimize the carbon footprint and make this information visible to all stakeholders. The retailer has selected the services of Cloud Computing Technology (CCT) to achieve this goal in minimum expenses. This private cloud, will map all the stakeholders of beef supply 
chain. Then, retailer will select the most effective, precise and user-friendly carbon calculator for all the stakeholders of beef supply chain and upload it on private cloud. All stakeholders can access it in the form of Software as a Service (SaaS) via basic Internet and computing equipment at their premises. Retailer will also provide appropriate training and user manuals regarding use of CCT to all the stakeholders. This CCT interface will consists of a carbon emission calculators and feedback in the form of a list of suggestive measures for mitigating carbon footprint corresponding to each stakeholder. The Figure 6 shows SaaS at farm end.

$<<$ Include figure $6>>$

Farmers will access the CCT interface via basic computing and Internet equipment. A window will pop up asking for the required information for calculation of carbon footprint at farm-end as shown in figure 6. The farmer will feed the required information and new window will pop up which will give the carbon footprint results and feedback to mitigate them. This phenomenon is shown in figure 7.

$<<$ Include figure $7>>$

The current carbon footprint is calculated using the information entered by farmer as $16 \mathrm{~kg} \mathrm{CO}$ eq. The feedback is generated in the form of a list of suggestive measures corresponding to the information entered by farmer. For example, it will suggest the farmers, which breed and feed will generate minimum carbon emission. It also shows the net reduction ( $2 \mathrm{~kg} \mathrm{CO}_{2}$ eq.) in carbon footprint, which could be achieved as compared to current carbon footprint. Farmers will take optimal decision and will bring relevant changes in their farming practices. Finally, they will utilize this calculator again and measure their carbon footprint. The information entered by the farmer and the results obtained at farm end will be visible to all stakeholders via private cloud. This information can be used by other stakeholders to reduce their carbon footprint at their end by mitigating the dependent factors or carbon hotspots. For example, logistics providers will identify if some delay or inefficiency in operation at their end is leading to unnecessary carbon emission at farms. They will coordinate with farmers and address that issue. The CCT interface for logistics is generic in nature. Any logistics firm can deploy it, which can be either logistics firm operating between farm to abattoir and processor or between abattoir and processor to retailer. These firms will individually deploy their respective CCT interface and a new window will open. They will enter the relevant information and obtain results regarding carbon emission. The calculator will also give them feedback to reduce their carbon footprint. For example, it will give suggestion in terms of using alternative fuel or cleaner mode of transport like rail freight. Finally, they will use the calculator again and measure their carbon footprint. The information entered by logistics and corresponding results will be visible to all stakeholders. This phenomenon will generate opportunities for other stakeholders to help logistics in reducing their carbon footprint in terms of dependent factors. For example, logistics will receive the information from beef farmers like the number of cattle, date and venue of collection of cattle etc. via private cloud. They will also receive the information in advance about the weight, sex etc. of cattle so that logistics can make proper arrangements for their transport keeping the space allowance and other 
government guidelines in mind in terms of animal handling while transportation. This phenomenon will improve the coordination of logistics with other stakeholders. The calculator will also suggest the best possible route in which the journey can be completed within the maximum journey time permitted by the government regulations, taking into account the carbon emission. Since, the emission results of all stakeholders are visible on the private cloud, one logistics firm can observe the operations and procedures of other logistics firms to improve and modify their process. The logistics between abattoir and processor and retailer are much complex, as their vehicles are temperature sensitive. Still, these firms can learn from the good practices of each other as well as identify bad practices followed at their end. This will further help them to optimize their carbon emissions. Similarly, the branches of abattoir and processor will enter the required information and obtain the results of the carbon footprint associated with them. These calculators will also give them feedback to reduce their carbon footprint. Abattoir and processor will also deploy the finding on private cloud and this information will be visible to all stakeholders. Similarly, retailer stores, which are located at different geographical locations, will individually deploy the CCT interface for them. They will enter the mandatory information in it and obtain the results corresponding to their carbon emission. The calculator will also give them feedback to reduce their carbon footprint. For example, it will suggest the use of clean energy derived from renewables rather than the one derived from fossil fuels. It will also suggest the good practices to be followed in a particular store in comparison to other stores like following appropriate stacking and shelving procedures and extra caution in handling the product etc. It will also emphasize the store managers to use modern techniques for forecasting the demand of the consumers. Consequently, the retailer stores will take optimal decision and will bring relevant changes in their operation. When all the retailer stores implement these procedures at their respective premises then the overall carbon footprint at the retailer end will be reduced. The proposed cloud will also help retailer stores to reduce their carbon footprint by mitigating their dependent factors and carbon hotspots.

In this way, the initiative taken by retailer to minimize carbon footprint will bring rewards to all stakeholders without disturbing their financial budget. It is particularly beneficial to small-scale stakeholders whether it is a beef farmer or logistic firm as they are not able to purchase carbon calculator on their own. The most appropriate, user-friendly carbon calculators are made available to all stakeholders at minimum cost. The carbon footprint of entire beef supply chain will be optimized using an integrated approach.

\section{Managerial implications}

This paper suggests an integrated system to measure and minimize carbon footprint of entire beef supply chain by utilizing the services of CCT. The proposed system will be particularly useful for managers of small and medium size stakeholders involved in beef supply chain as these firms lack in resources, infrastructure and awareness of carbon emission from their operations. This approach will save them from individually purchasing carbon calculators as they can access them in the form of SaaS from private cloud.

All stakeholders will access the private cloud provided by the retailer and enter the relevant information in the carbon calculator uploaded on it in the form of SaaS and obtain the carbon footprint results. These results and information will be accessible by 
managers and policymakers of all stakeholders. The calculator will also give them feedback to reduce their carbon footprint. This phenomenon will help the managers of various stakeholders in appropriate decision-making and thereby increasing their productivity and curbing their carbon emission. For example, it will suggest the farmers which breed of beef is having the least carbon emission. This study will help the managers to identify, which segment is weak in terms of product flow and carbon emission and it could be rectified with the suggestive measures provided by the carbon calculators.

As cloud is mapping the entire beef supply chain, it will also help in mitigating carbon emission of a particular stakeholder caused due to its dependency on other stakeholder. For example, it will highlight the feasible options available to manager of logistics to reduce carbon footprint by mitigating their carbon hotspots, which are dependent on retailer. It will also help to identify the good practices and bad practices followed by a particular stakeholder in terms of carbon emission. For example, there might be different logistics firms deployed from farm and abattoir \& processor and from abattoir and processor to retailer. The managers of these firms can utilize the carbon emission information associated with each other to identify the bad practices followed by them and thereby follow the better approach. This study can remarkably influence the conventional method of measurement of carbon footprint at one end (stakeholder) of beef supply chain. It will further help in improving the coordination of managers of all stakeholders in terms of efficient and eco-friendly product flow. For example, it will boost the coordination of managers of logistics and farmer in planning in advance, the transportation of cattle and the special needs to be taken into account like space allowance, maximum journey time of cattle etc.

Customers, nowadays, have become very selective about the traceability of beef especially after the horsemeat scandal in the UK. The information visibility aspect of CCT utilized in this study will promptly address this issue. Therefore, it will help the managers of retailer to charge the premium price to consumers in facilitating traceability for them. Similarly, the customers are also gradually getting curious about the carbon footprint associated with the products they purchase. This issue can be addressed by this study and could be capitalized by the retailer in their promotion of transparency to customers or in terms of selling sustainable products. Finally, it will help the managers and policymakers of retailers to identify the segments of its supply chain, which needs to be modified to achieve the government's target of reduced carbon budget.

In this way, carbon hotspots for the entire beef supply chain can be identified, quantified and then prioritized while optimizing them. Moreover, all the managers associated with beef supply chain can continuously monitor their progress in reducing their carbon footprint, as their past records will be stored in the database of private cloud.

\section{Conclusion}

Carbon emission is occurring at different stages in the beef supply chain. In the past, stakeholders were only bothered about their profit and productivity. However, nowadays, they are also concerned about the carbon footprint generated from their operations as well because of the pressure from government authorities. Some of the stakeholder's especially small and medium size stakeholders of beef supply chain are 
not capable to address this issue because of scarcity of financial resources and knowledge. There is also lack of coordination among the stakeholders as there is no single platform where they can reveal their respective carbon emission details. Keeping these crucial discrepancies in mind, this article proposes collaborative, integrated and centric approach of optimizing and measuring carbon footprint of entire beef supply chain by using Cloud Computing Technology (CCT). Initially, carbon hotpots are identified for all stakeholders viz. farm, logistics, abattoir \& processor, retailer. Thereafter, retailer develops private cloud, to map the entire beef supply chain regardless of their geographical locations. Carbon footprint associated with the product flow of beef, from farm to the retailer will be optimized and measured. It will also boost the coordination among the stakeholders thereby making their operations more efficient and environment friendly. Step-by-step execution process of proposed system has been described in the case study section. This paper has the further scope of pilot study with real time data from all the stakeholders.

\section{References}

1. Shaw, K., Shankar, R., Yadav, S. S. \& Thakur, L.S. (2013), Modeling a lowcarbon garment supply chain, Production Planning and Control, Volume 24(89), 851-865

2. Peters, Gregory M., Rowley, H. V., Wiedemann, S., Tucker, R., Short, M. D., \& Schulz, M. (2012). "Red meat production in Australia: life cycle assessment and comparison with overseas studies." Environmental science \& technology 44.4 (2010): 1327-1332.

3. Desjardins, R. L., Worth, D. E., Vergé, X. P., Maxime, D., Dyer, J., \& Cerkowniak, D. (2012). "Carbon Footprint of Beef Cattle." Sustainability 4.12 3279-3301.

4. Kythreotou, N., Tassou, S. A., \& Florides, G. (2011). The contribution of direct energy use for livestock breeding to the greenhouse gases emissions of Cyprus. Energy, 36(10), 6090-6097.

5. Bustamante, M. M., Nobre, C. A., Smeraldi, R., Aguiar, A. P., Barioni, L. G., Ferreira, L. G., Longo, K., May, P., Pinto, A.S., \&Ometto, J. P. (2012). "Estimating greenhouse gas emissions from cattle raising in Brazil". Climatic change, $115(3-4), 559-577$.

6. Schroeder, R., Aguiar, L. K., \&Baines, R. (2012). Carbon footprint in meat production and supply chains. Journal of Food Science and Engineering, 2, 652-665.

7. Bellarby, J., Tirado, R., Leip, A., Weiss, F., Lesschen, J. P., \& Smith, P. (2013). Livestock greenhouse gas emissions and mitigation potential in Europe. Global change biology, 19(1), 3-18.

8. Ogino, A., Orito, H., Shimada, K., \& Hirooka, H. (2007). Evaluating environmental impacts of the Japanese beef cow-calf system by the life cycle assessment method. Animal Science Journal, 78(4), 424-432. 
9. Al-Hudhaif, S. and Alkubeyyer, A., (2011), "E-Commerce Adoption Factors in Saudi Arabia", International Journal of Business and Management, 6 (9), 122-33.

10. Hutchinson, C., Ward,J.,\&Castilion,K.(2009).Navigating the next-generation application architecture. IT Professional, 1(2), 18-22.

11. Sean Marston, ZhiLi, Subhajyoti.B, Juheng.Z, Anand. G (2011). Cloud Computing - The business prospective. Decision Support Systems 51 (2011) 176-189.

12. XuanXu.(2012). From Cloud computing to Cloud Manufacturing. Robotics and Computer-Integrated Manufacturing 28,75-85.

13. EBLEX (2012). Down to earth. Project report on The beef and sheep roadmap phase three.

14. Forster, P., V. Ramaswamy, P. Artaxo, T. Berntsen, R. Betts, D.W. Fahey, J. Haywood, J. Lean, D.C. Lowe, G. Myhre, J. Nganga, R. Prinn, G. Raga, M. Schulz and R. Van Dorland, 2007: Changes in Atmospheric Constituents and in Radiative Forcing. In: Climate Change 2007: The Physical Science Basis. Contribution of Working Group I to the Fourth Assessment Report of the Intergovernmental Panel on Climate Change[Solomon, S., D. Qin, M. Manning, Z. Chen, M. Marquis, K.B. Averyt, M.Tignor and H.L. Miller (eds.)]. Cambridge University Press, Cambridge, United Kingdom and New York, NY, USA.

15. Carbon Trust, UK (2012).A management guide on carbon footprinting: The next step to reducing your emission. Retrieved on March 27, 2014 from http://www.carbontrust.com/media/44869/j7912_ctv043_carbon_footprinting aw_interactive.pdf

16. Barker G and Davey E, (2014). Policy on Reducing the UK's green house gas emissions by $80 \%$ by 2050. Retrieved on March 27, 2014 from https://www.gov.uk/go vernment/policies/reducing-the-uk-s-greenhouse-gasemissions-by-80-by-2050/supporting-pages/carbon-bud gets.

17. Boucher D, Elias P, Goodmen L, May- Tobin C, Mulik K and Roquemore S. (2012). Grade A choice? Solutions for deforestation free meat. Retrieved on March 27, 2014 from http://www.ucsusa.org/global_warming/solutions/stopdeforestation/solutions-for-deforestation-free-meat.html

18. Environmental Protection Agency- 2012 U.S. Greenhouse Gas Inventory Report: Inventory of U.S. Greenhouse Gas Emissions and Sinks: 1990-2010 (April 2012) http://www.epa.gov/climatechange/emissions/downloads12/US GHG-Inventory-2012-ES.pdf

19. Attaran, M. and Attaran, S., (2007) "Collaborative supply chain management: The most promising practice for building efficient and sustainable supply chains", Business Process Management Journal, Vol. 13 Iss: 3, pp.390 - 404

20. Angela Lin, and Nan-Chou Chen, (2012). "Cloud computing as an innovation: Perception, attitude, and adoption ", International Journal of Information Management 32, 533-540. 
21. Banerjee, P. (2009), "An intelligent IT infrastructure for the future", Proceed ings of 15th International Symposium on High-performance Computer Architecture, HPCA, Raleigh,NC, USA.

22. Buyya, R., Yeo, C. S., \&Venugopal, S. (2008). Market-oriented cloud computing: Vision, hype, and reality for delivering it services as computing utilities. In Proceeding of 10th IEEE international conference on high performance computing and communications Dalian, China, September, (pp. 5-13).

23. Buyya, R., Yeo, C.S., Venugopa, S., Broberg, J. and Brandic, I. (2009), "Cloud computing and emerging it platforms: vision, hype, and reality for delivering computing as the 5thutility", Future Generation Computer Systems, Vol. 25, pp. 599-616.

24. Goscinski, A. and Brock, M. (2010), "Toward dynamic and attribute based publication, discovery and selection for cloud computing", Future Generation Computer Systems, Vol. 26, pp.947-70.

25. Greer, M. (2009). Software as a service inflection point: Using cloud computing to achieve business agility. New York: Global Authors Publishers.

26. Garnett, T. (2009). "Livestock-related greenhouse gas emissions: impacts and options for policy makers". Environmental science \& policy, 12(4), 491-503.

27. Capper, J. L. (2011). "The environmental impact of beef production in the United States: 1977 compared with 2007”. Journal of animal science, 89(12), 4249-4261.

28. Nguyen, T. L. T., Hermansen, J. E., \& Mogensen, L. (2010). Environmental consequences of different beef production systems in the EU. Journal of Cleaner Production, 18(8), 756-766.

29. Pelletier, N., Pirog, R., \& Rasmussen, R. (2010). Comparative life cycle environmental impacts of three beef production strategies in the Upper Midwestern United States. Agricultural Systems, 103(6), 380-389.

30. Hermansen, J. E., \& Kristensen, T. (2011). Management options to reduce the carbon footprint of livestock products. Animal Frontiers, 1(1), 33-39.

31. Green, J. C., Caracelli, V. J., \& Graham, W. F. (1989). Toward a conceptual framework for mixed-method evaluation designs. Educational Evaluation and Policy Analysis, 11 (3), 255-274.

32. DEFRA, UK. Welfare of Animals During Transport. Retrieved on March 27, 2014https://www.gov.uk/government/uploads/system/uploads/attach ment data/file/69387/pb12544a-transport-cattle-110315.pdf 
